\title{
Special Issue Focus: Selected Papers from the 5th Symposium on Damage Mechanism in Materials and Structures
}

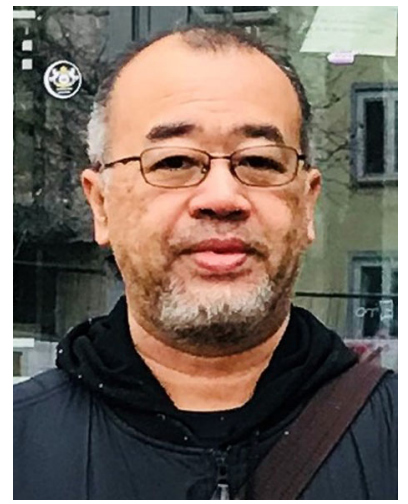

Shahrum Abdullah

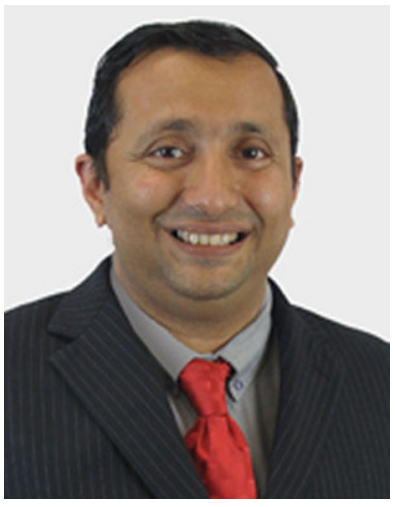

Salvinder Singh Karam Singh
This special issue of the Journal of Failure Analysis and Prevention presents a selection of articles based on presentations at the 5th Symposium on Damage Mechanism in Materials and Structures (SDMMS 20-21) and expanded into full-length, peer-reviewed articles. The conference was held in Penang, Malaysia, on March 8-9, 2021, and was jointly organized by Universiti Teknologi Mara, Cawangan Pulau Pinang, and Universiti Kebangsaan, Malaysia. The symposium was initially planned for 2020 , but due to the COVID-19 pandemic and the restrictions set forth by the government, the organizing committee decide to organize it virtually in 2021. Despite the long-lasting impact of the COVID-19 pandemic, more than 100 participants from both academia and industry attended the conference virtually. They joined for keynote lectures from the UK, Thailand, and Malaysia, invited oral presentations, and academic discussions during the conference.
Engineering components or structures are often designed to ensure they perform to a given desired function throughout the life of the design. The techniques of deterministic and nondeterministic employ a nominal or mean quantity when comparing the calculated stresses against the strength of the material for an intended life. However, the continuous pursuit of damage mechanism in materials and structures in civil and mechanical engineering is important as it will assist in the performance with lighter structures and improved desired durability and reliability.

In this respect, the knowledge of the response of the materials to the operating load and environment is indispensable for the safe operation of the structures. The mechanical response of the failure consists of two aspects, namely the damage mechanisms and the application of numerical analysis for assessing this kind of failure. In this 
respect, the 5th Symposium on Damage Mechanism in Materials and Structures (SDMMS 20-21) was successfully organized to address numerous design-related issues on the response of the materials to the applied load and environment for the field of civil and mechanical engineering.

This special issue in the Journal of Failure Analysis and Prevention has compiled the current technical manuscripts on the method of assessing the damage, the characterization techniques, and sample applications of the analysis to engineering materials and structures. The assessment methods include the traditional analysis, the signal processing, finite element analysis, statistical, and probabilistic approaches. Several characterization studies, including stress analysis by computational simulation, limit-load analysis, material performance, component and structural integrity assessment, and fatigue analysis under both constant and variable amplitude loading spectrums, are highlighted.

\section{Shahrum Abdullah \\ Guest Editor}

Department of Mechanical and Manufacturing

Engineering

Faculty of Engineering and Built Environment

Universiti Kebangsaan, Malaysia

Contact e-mail: shahrum@ukm.edu.my

\section{Salvinder Singh Karam Singh}

\section{Guest Editor}

Department of Mechanical and Manufacturing

Engineering

Faculty of Engineering and Built Environment

Universiti Kebangsaan, Malaysia

Contact e-mail: salvinder@ukm.edu.my

Publisher's Note Springer Nature remains neutral with regard to jurisdictional claims in published maps and institutional affiliations. 